\title{
Robust Estimation Methods Used to Study the Reasons behind Increasing Divorce Cases in Saudi Society
}

\author{
Alanazi Talal Abdulrahman $\mathbb{D D}^{1}$ and Osama Alamri $\mathbb{i D}^{2}$ \\ ${ }^{1}$ Department of Mathematics, University of Ha'il, Ha'il, Saudi Arabia \\ ${ }^{2}$ Department of Statistics, University of Tabuk, Tabuk, Saudi Arabia \\ Correspondence should be addressed to Alanazi Talal Abdulrahman; t.shyman@uoh.edu.sa
}

Received 24 June 2021; Accepted 4 August 2021; Published 12 August 2021

Academic Editor: Ishfaq Ahmad

Copyright ( $) 2021$ Alanazi Talal Abdulrahman and Osama Alamri. This is an open access article distributed under the Creative Commons Attribution License, which permits unrestricted use, distribution, and reproduction in any medium, provided the original work is properly cited.

\begin{abstract}
Background. Increasing divorce rates is a major problem in Saudi society. Divorce has become the primary solution for many couples who are experiencing problems in their relationships, and the language of divorce has become prevalent in both the daily register of Saudi courts on a daily basis and in fictional works. This trend has become a threat to marital life and is particularly damaging for children and young people. There has been previous research on the increase in divorce rates; however, no one addresses this important issue statistically. The specific research question is what are the actual reasons for the increase in divorce rates mentioned in previous studies? Objective. This study contains a statistical analysis of the underlying reasons for rising divorce rates in Saudi society. Methods. An online survey was conducted that gathered quantitative data from 800 participants. The responses of factual relevance were examined via edge plan analysis, regression analysis, and analyses with SPSS software to determine the causes for the rise in divorces in Saudi society. A predesign of edge consisting of six factors and twelve trials is selected. The design is examined in all the data for each row of it and according to the factor or reason chosen, provided that all design items are fulfilled; after that, it is analyzed in two ways. Results. Some examples are presented, so the findings indicated that differences on the couple's characters and the length of time the wife spent doing housework and amount of attention to the husband are factors that contributed to divorce. Conclusion. The Saudi Arabian government needs to develop an operational plan to study these causes of divorce and take action. Future studies could analyze the data using supersaturated prototypes, where a large number of variables are studied in just a few simulation trials.
\end{abstract}

\section{Introduction}

Some people believe that God legalized marriage in order to fortify the human soul and fulfill its desires, and Islamic law has laid down rules and regulations for this noble relationship. This regulation is meant to protect the ties of affection, mercy, and peace, instilling the feelings of permanence and continuity to them. If, however, the marriage has ceased to be peaceful, lacks mercy between the spouses, and has numerous problems that are difficult to solve, then divorce is prescribed as the final solution. In this case, God blesses and grants peace. Divorce is defined linguistically as a lifting of marital restrictions and a dissolution of bonds. Married couples face many problems and disagreements that may lead to separation if the couple lacks endurance or cannot find appropriate solutions to resolve disputes. Ultimately, this leads to divorce, which is known in Sharia law as the dissolution of the marriage contract. Saudi courts recorded 53,000 divorces in 2017-a rate of 149 divorce cases per day-in addition to the hundreds of cases that occurred outside the courts. One study found that, for every 10 marriages, there are 3 divorce cases, meaning that a third of married couples get divorced or are divorce proceedings [1].

The focus of this paper is to contain a statistical analysis of the underlying reasons for rising divorce rates in Saudi society. The responses of factual relevance from online survey were examined via edge plan analysis, regression analysis, and analyses with SPSS software to determine the causes for the rise in divorces in Saudi society. We begin by 
introducing the literature review and theoretical framework in Section 2. In Section 3, we outline the methodology. In Section 4, data analysis and some examples are presented. We conclude the paper in Section 5.

\section{Literature Review and Theoretical Framework}

In this section, we develop our theoretical framework in literature review. The specific research question is what are the actual reasons for the increase in divorce rates mentioned in previous studies? We focus on the concept of the actual reasons for the increase in divorce rates. Hezarjaribi et al. [2] found that the reasons underlying the rise in divorce cases in Saudi society include incompatibility between spouses, sharing a residence with the wife's family or the husband's family, and economic development and social transformation in the Kingdom of Saudi Arabia. Anees [3] stated that a lack of religious awareness between spouses, their financial situation, and influence of modern technology are among the most important factors contributing to the increase in divorce cases in Iraqi society.

Aqeel [4] mentioned in his comprehensive study on this topic; the reasons are limited to the following: weakness of faith, ignorance, intolerance of the lack of awareness of the problem, lack of knowledge of the rights spouses are obligated to fulfill, and poor good choice of spouse. Alhayajneh and Wael Abujalban [5] stated that the reasons for increased divorce rates in Jordan consist of the following: lack of focus on character by all spouses, lack of concern for guests, lack of maintenance of the house/property, and careless spending by the wife. The study conducted by Majali [6] aimed to uncover the most important social causes leading to divorce in the Karak governorate, and the following were identified: ignorance of marital life, suspicion of jealously, and interference of relatives in marital problems. The results from AlJundi [7] study indicate that the main factors leading to divorce are wrong choice of spouse, mutual lack of respect, mistreatment, insult, and physical abuse. The data from AlMaamari [8] study indicate that the reasons underlying divorce in the sample of divorced women from the Sultanate of Oman include emotional distress, presence of children and woman's neglect of her husband's rights after childbearing, religious differences, and severe interference by the couple's family. The study conducted by LAA entitled the following. Early divorce: its causes and manifestations in the Emirate of Sharjah (a field study in the Emirate of Sharjah) found the following reasons for divorce: one spouse overindulges on luxuries and men's suspicious relationships on social networking sites. The study by Gigy and Kelly [9] revealed that the factors that lead to divorce are unfulfilled emotional needs, lifestyle differences or boredom with marriage, intense conflict, and abusive relationships. Thurnher et al. [10] investigated the causes of divorce as reported by a sample of 333 men and women between the ages of 20 and 79. They found that the reasons for divorce ranged from personal nonfulfillment of obligations to nonfulfillment of the obligations of the marital role. Judges in the Sharia courts confirmed that many divorces there originated from women working outside the home. Thi [11] features changes in the reasons for divorce in the South in examination with past separate from concentrates in the North of Vietnam and talks according to modernization, independence, and sex fairness. Conventional content analysis of Osafo et al. [12] study distinguished six fundamental elements' reasons for divorce: unfaithfulness, misuse, monetary help, closeness, monetary issues, outsider interruption, and sexual orientation job belief system. Nakhaee et al. [13] revealed that the factors that lead to divorce are the separation searchers who gave clarification to their choice; three were conspicuous: the failure to determine clashes, which prompted questions, disappointment with the way their mates communicated their affection and feelings, and discontent in regards to a life partner's character attributes. However, there has been an increased interest in defining new statistical models or new families of statistical models to provide a better description of the problems under consideration. For more details, we refer to Zuo et al. [14], Zhao et al. [15], and Bo et al. [16].

Hezarjaribi et al. [2]l, Aqeel [4], and Alhayajneh and Wael Abujalban [5] studies are the most relevant to the aims of this study, given the actual reasons for the increase in divorce rates. Although, Gigy and Kelly [9], like Hezarjaribi et al. [2], say that lifestyle differences or boredom with marriage is the factor that leads to divorce. From the work of Anees [3], Majali. [6], AlJundi [7], and LAA, the findings of the aforementioned research do not agree with the findings of our study.

\section{Methodology}

3.1. Target Population and Study Sample. For this study, a questionnaire was distributed to the Saudi community. Additionally, an online survey was conducted to gather quantitative data from 800 participants. The information comes from surveys contacted in courts in Saudi Arabia. The information is gathered by the center courts in the country and is accessible to Saudi Arabian resident.

3.2. Data Collection. The questions asked respondents to support or reject the reason provided, which are shown in Table 1, which generated clear data. Regression analysis and the edge structure procedure were conducted on the data to determine the driving factors in the increase in divorce cases in Saudi society.

3.3. Sample Selection. A predesign of edge consisting of six factors and twelve trials is selected (see Table 2). The design is examined in all the data for each row of it and according to the factor or reason chosen, provided that all design items are fulfilled; after that, it is analyzed in two ways.

\subsection{Consolidating and the Distinctive Examination Technique.} The design chosen in the previous step was analyzed using the edges and regression methods. If the factors obtained using the edge design method were the same as those obtained using the regression method, then they were 
TABLE 1: Two levels of the causes behind the rise of divorce cases.

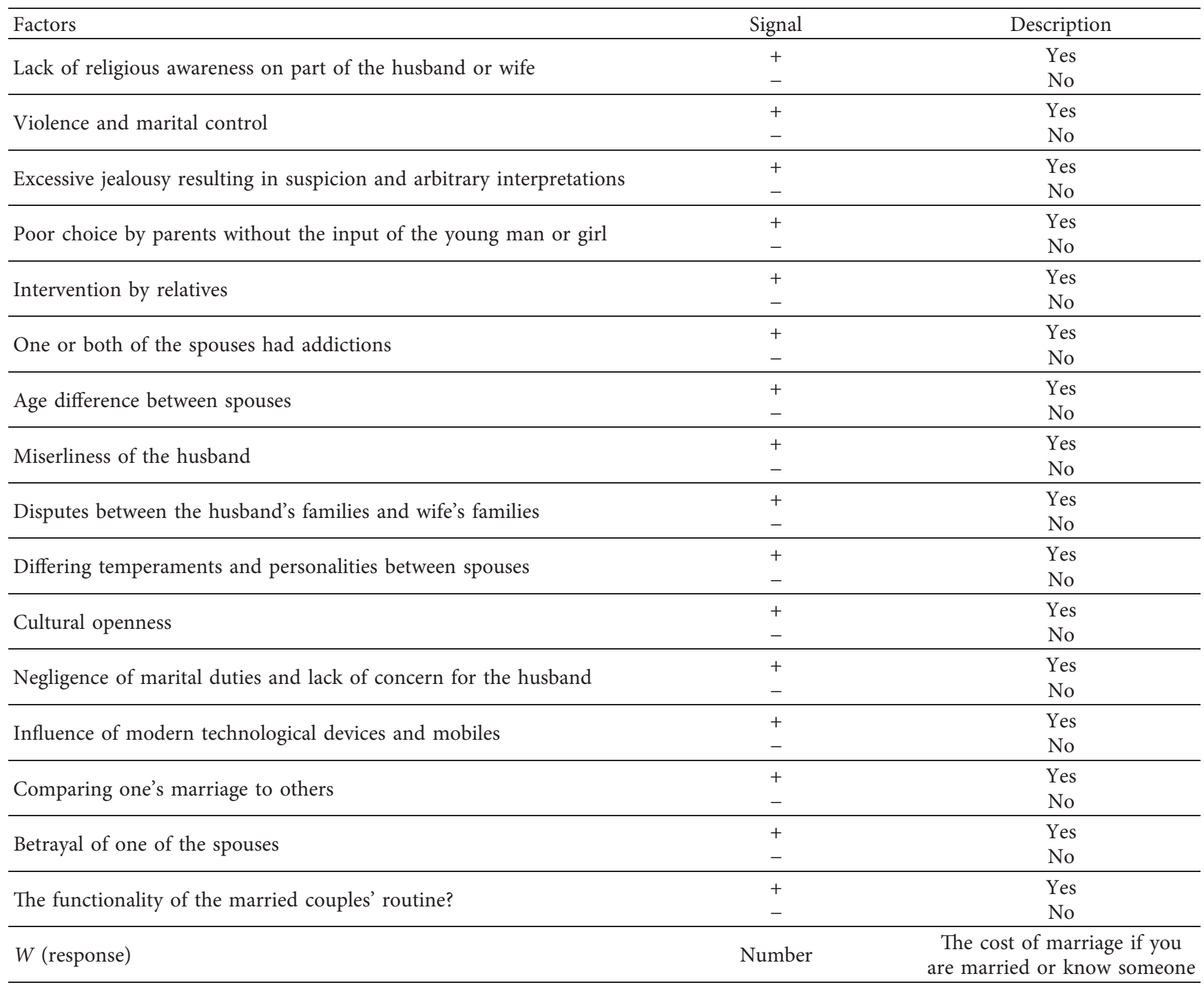

considered the actual causes of divorce cases in Saudi society. We use the edge design method here, which is a purely and accurate statistical method and not a method based on assumptions, by gradually reducing the factors so that we can search for the actual factor of any problem and social phenomenon.

\section{Data Analysis}

The statistical significance of the questionnaire was determined using edge design analysis and regression analysis. Elster and Neumaier [17] presented edge plans, which depend on a model-self-sufficient test that can be used for dynamic components. To identify the unique factors, the assessments are used as coordinates in a social event of $E$ sets. In this strategy, the assessments contrast in a solitary part. This is typical in screening tests, and basically, all differentiations,

$$
q_{i, j}:=w_{i}-w_{j}, \quad(i, j) \in E,
$$

involve racket so to speak. If we acknowledge that the noise in the data is a added substance, commonly scattered with zero mean and contrast $\sigma^{2}, n-p$ of $q_{i, j}$ are routinely appropriated with zero mean and vacillation $2 \sigma^{2}$. Because of the unknown number of outliers, the change ought to be surveyed in a robust way. For example, the following center check can be used:

$$
\tilde{\sigma}=\frac{\operatorname{midpoint}\left\{\left|q_{i, j}\right|:(i, j) \in E\right\}}{\sqrt{2} \times 0.675} .
$$

Alanazi et al. [18] provide more details about this method. In order to address these ethical concerns, the following examples will be considered.

Example 1. Assume that there are six data points: lack of religious awareness on part of the husband or wife $x_{1}$, violence and marital control $x_{2}$, excessive jealousy resulting in suspicion and arbitrary interpretations $x_{3}$, poor choice by parents without the input of the young man or girl $x_{4}$, 
TABle 2: The design selected in whole data.

\begin{tabular}{lcccccc}
\hline Run & $x_{1}$ & $x_{2}$ & $x_{3}$ & $x_{4}$ & $x_{5}$ & $x_{6}$ \\
\hline 1 & + & + & - & + & + & + \\
2 & - & + & + & + & + & + \\
3 & + & - & + & + & + & + \\
4 & - & - & - & + & - & + \\
5 & - & - & - & + & + & - \\
6 & - & - & - & - & + & + \\
7 & - & + & - & + & + & + \\
8 & - & - & + & + & + & + \\
9 & + & - & - & + & + & + \\
10 & - & - & - & - & - & + \\
11 & - & - & - & + & - & - \\
12 & - & - & - & - & + & - \\
\hline
\end{tabular}

intervention by relatives $x_{5}$, and one or both of the spouses had addictions $x_{6}$.

From Table 3, the following steps are obtained. First, the authors subtracted each value present in $W$ so that the first element was subtracted from the seventh element and so on, until six different elements are acquired, as presented in Table 4. Second, the authors calculated the median for all the elements in the first step by using $p$ as the influencing factor. The authors then calculated the $O(p)$ and $k * 2^{0.5} \sigma$ values. Finally, if the value of $O(p)$ was greater than $p$, the authors stopped progressing through the steps and searched for the influencing factors. Table 5 shows the results of the previous steps, which revealed four factors that contributed to increase in divorce cases, which are lack of religious awareness on part of the husband or wife, violence and marital control, intervention by relatives, and one or both of the spouses had addictions.

Again using the data from Table 3, a regression analysis was conducted using the SPSS statistical program, which revealed that there were no influencing factors that led to the increase in divorce cases and resulted in the following statistical equation: $w=80000+\varepsilon$ with $R-s g=55.3 \%$, mean $=95000$, and standard deviation $=36306.77$. The residual was normal because value of 0.200 was obtained, which is greater than 0.05 . Based on the results above, the authors note the following: the edge design analysis produced four influencing factors that contributed to the increase in divorce cases, namely, lack of religious awareness on part of the husband or wife, violence and marital control, intervention by relatives, and one or both of the spouses had addictions, while the regression analysis did not produce any influencing factors. In conclusion, the authors conclude that there are no influencing factors that have led to the increase in divorce cases.

Example 2. Suppose that there are six data points and there are differing temperaments and personalities between spouses $x_{1}$, cultural openness $x_{2}$, negligence of marital duties and lack of concern for the husband $x_{3}$, influence of modern technological devices and mobiles $x_{4}$, comparing one's marriage to others $x_{5}$, and betrayal of one of the spouses $x_{6}$.

We refer to the data in Table 6 and use the edge design method mentioned in Example 1. Based on Tables 7 and 8 ,
TABle 3: One replicate for Example 1.

\begin{tabular}{lcccccccc}
\hline Run & $x_{1}$ & $x_{2}$ & $x_{3}$ & $x_{4}$ & $x_{5}$ & $x_{6}$ & $\mathrm{~W}$ & Response number \\
\hline 1 & + & + & - & + & + & + & 60000 & 5 \\
2 & - & + & + & + & + & + & 60000 & 6 \\
3 & + & - & + & + & + & + & 120000 & 67 \\
4 & - & - & - & + & - & + & 120000 & 43 \\
5 & - & - & - & + & + & - & 30000 & 59 \\
6 & - & - & - & - & + & + & 110000 & 35 \\
7 & - & + & - & + & + & + & 150000 & 70 \\
8 & - & - & + & + & + & + & 90000 & 9 \\
9 & + & - & - & + & + & + & 100000 & 3 \\
10 & - & - & - & - & - & + & 140000 & 586 \\
11 & - & - & - & + & - & - & 100000 & 125 \\
12 & - & - & - & - & + & - & 60000 & 55 \\
\hline
\end{tabular}

TABle 4: Model-independent checks using edge design for Table 1.

\begin{tabular}{lccccc}
\hline$x_{1}$ & $x_{2}$ & $x_{3}$ & $x_{4}$ & $x_{5}$ & $x_{6}$ \\
\hline-90000 & -30000 & 20000 & -20000 & -70000 & 50000 \\
90000 & 30000 & 20000 & 20000 & 70000 & 50000 \\
\hline
\end{tabular}

the authors conclude that there are two influencing factors that have contributed to the increase in divorce cases: differing temperaments and personalities between spouses and comparing one's marriage to others.

Given the results of the regression analysis conducted using the SPSS statistical program, the authors conclude that there is a factor that has influenced the increase in divorce cases: differing temperaments and personalities between spouses. The following equation was produced to explain this factor: $w=73000-35200 x_{1}+\varepsilon$ with $R-s g=79.2 \%$, the mean $=96000$, and the standard deviation $=45118.02$. The authors conclude that the edge design produced two influencing factors: differing temperaments and personalities between spouses and comparing one's marriage to others, while the regression analysis produced one factor: differing temperaments and personalities between spouses. Therefore, there is a factor that has influenced the increase in divorce cases in Saudi society: differing temperaments and personalities between spouses.

Example 3. Suppose that there are six data points, and there are both possess cultural openness $x_{1}$, negligence of marital duties and lack of concern for the husband $x_{2}$, influence of modern technological devices and mobiles $x_{3}$, comparing one's marriage to others $x_{4}$, betrayal of one of the spouses $x_{5}$, and the functionality of the married couples' routine? $x_{6}$.

Referring to the data in Table 9 and using the edge design method mentioned in Example 1. Based on Tables 10 and 11 , the authors conclude that there are four factors that influenced the increase in divorce cases, namely, cultural openness, negligence of marital duties, and lack of concern for the husband, comparing one's marriage to others and the functionality of the married couples' routine.

Based on the regression analysis conducted using the SPSS statistical program, the author concludes that there is a factor that influenced the increase divorce cases: negligence 
TABLE 5: Step-by-step calculations in the edge design analysis.

\begin{tabular}{cccccc}
\hline$p$ & Median & $\tilde{\sigma}(p)$ & $k 2^{(1 / 2)} \tilde{\sigma}(p)$ & $O(p)$ & $O(p)<p ?$ \\
\hline 0 & 40000 & 41902.62407 & 59259.25926 & 2 & No \\
1 & 30000 & 31426.96805 & 44444.44444 & 3 & No \\
2 & 25000 & 26189.14004 & 37037.03704 & 3 & No \\
3 & 20000 & 20951.31204 & 29629.62963 & 4 & No \\
4 & 20000 & 20951.31204 & 29629.62963 & 4 & No \\
5 & 20000 & 20951.31204 & 29629.62963 & 4 & Yes \\
\hline
\end{tabular}

TABLE 6: One replicate for Example 2.

\begin{tabular}{ccccccccc}
\hline Run & $x_{1}$ & $x_{2}$ & $x_{3}$ & $x_{4}$ & $x_{5}$ & $x_{6}$ & $\mathrm{~W}$ & Response number \\
\hline 1 & + & + & - & + & + & + & 50000 & 93 \\
2 & - & + & + & + & + & + & 150000 & 45 \\
3 & + & - & + & + & + & + & 30000 & 1 \\
4 & - & - & - & + & - & + & 150000 & 31 \\
5 & - & - & - & + & + & - & 22000 & 599 \\
6 & - & - & - & - & + & + & 120000 & 108 \\
7 & - & + & - & + & + & + & 150000 & 95 \\
8 & - & - & + & + & + & + & 100000 & 36 \\
9 & + & - & - & + & + & + & 80000 & 60 \\
10 & - & - & - & - & - & + & 120000 & 12 \\
11 & - & - & - & + & - & - & 100000 & 250 \\
12 & - & - & - & - & + & - & 80000 & 50 \\
\hline
\end{tabular}

TABLE 7: Model-independent checks with edge design for Table 9.

\begin{tabular}{lccccc}
\hline$x_{1}$ & $x_{2}$ & $x_{3}$ & $x_{4}$ & $x_{5}$ & $x_{6}$ \\
\hline-100000 & 50000 & -50000 & 30000 & -78000 & 40000 \\
100000 & 50000 & 50000 & 30000 & 78000 & 40000 \\
\hline
\end{tabular}

TABLE 8: Step-by-step calculations for the edge design analysis.

\begin{tabular}{cccccc}
\hline$p$ & Median & $\tilde{\sigma}(p)$ & $k 2^{(1 / 2)} \tilde{\sigma}(p)$ & $O(p)$ & $O(p)<p ?$ \\
\hline 0 & 50000 & 52378.28009 & 74074.07407 & 2 & No \\
1 & 50000 & 52378.28009 & 74074.07407 & 2 & No \\
2 & 45000 & 47140.45208 & 66666.66667 & 2 & No \\
3 & 40000 & 41902.62407 & 59259.25926 & 2 & Yes \\
\hline
\end{tabular}

TABLE 9: One replicate for Example 3.

\begin{tabular}{lcccccccc}
\hline Run & $x_{1}$ & $x_{2}$ & $x_{3}$ & $x_{4}$ & $x_{5}$ & $x_{6}$ & $\mathrm{~W}$ & Response number \\
\hline 1 & + & + & - & + & + & + & 150000 & 346 \\
2 & - & + & + & + & + & + & 150000 & 144 \\
3 & + & - & + & + & + & + & 70000 & 523 \\
4 & - & - & - & + & - & + & 150000 & 122 \\
5 & - & - & - & + & + & - & 100000 & 128 \\
6 & - & - & - & - & + & + & 65000 & 352 \\
7 & - & + & - & + & + & + & 200000 & 74 \\
8 & - & - & + & + & + & + & 18000 & 596 \\
9 & + & - & - & + & + & + & 50000 & 145 \\
10 & - & - & - & - & - & + & 100000 & 10 \\
11 & - & - & - & + & - & - & 80000 & 50 \\
12 & - & - & - & - & + & - & 120000 & 489 \\
\hline
\end{tabular}

of marital duties and lack of concern for the husband. The following equation explains this factor: $W=126166.667+$ $49800 x_{2}+\varepsilon$ with $R-s g=86.2 \%$, the mean $=104416.66$, and the standard deviation $=51711.53$. The authors conclude that
TABle 10: Model-independent checks with the edge design for Table 9.

\begin{tabular}{lccccc}
\hline$x_{1}$ & $x_{2}$ & $x_{3}$ & $x_{4}$ & $x_{5}$ & $x_{6}$ \\
\hline-50000 & 132000 & 20000 & 50000 & 20000 & -55000 \\
50000 & 132000 & 20000 & 50000 & 20000 & 55000 \\
\hline
\end{tabular}

TABLE 11: Step-by-step calculations for the edge design analysis.

\begin{tabular}{cccccc}
\hline$p$ & Median & $\tilde{\sigma}(p)$ & $k 2^{(1 / 2)} \tilde{\sigma}(p)$ & $O(p)$ & $O(p)<p ?$ \\
\hline 0 & 50000 & 52378.28009 & 74074.07407 & 2 & No \\
1 & 50000 & 52378.28009 & 74074.07407 & 2 & No \\
2 & 35000 & 36664.79606 & 51851.85185 & 3 & No \\
3 & 20000 & 20951.31204 & 29629.62963 & 4 & No \\
4 & 20000 & 20951.31204 & 29629.62963 & 4 & No \\
5 & 20000 & 20951.31204 & 29629.62963 & 4 & Yes \\
\hline
\end{tabular}

the edge design analysis produced four influencing factors, namely, cultural openness, negligence of marital duties and lack of concern for the husband, comparing one's marriage to others, and functionality of the married couples' routine, while the regression analysis produced one influencing factor: negligence of marital duties and lack of concern for the husband. Ultimately, this results in one consistent factor that has influenced the increase in divorce cases in Saudi society: negligence of marital duties and lack of concern for the husband.

\section{Conclusion}

Statistics and official reports in recent years show a significant increase in divorce rates in the Kingdom of Saudi Arabia, which confirms the existence of a clear defect in the family system and a societal problem that needs to be appropriately resolved. These statistics confirm the seriousness of the phenomenon of divorce on the social structure and its functions because it is linked to the most influential social systems in the lives of individuals and society in general, and it is the most despised to God Almighty. Also, statistics confirm, unfortunately, that Saudi society is at the forefront of societies that suffer from an increase in the phenomenon of divorce year after year. Although this phenomenon has been researched, studied, and written at all official, media, and social levels, unfortunately, this phenomenon is still growing year after year. These studies and research have not succeeded in treating this phenomenon. However, no one addresses this important issue statistically. The specific research question was what are the actual reasons for the increase in divorce rates mentioned in previous studies? This study contains a statistical analysis of the underlying reasons for rising divorce rates in Saudi society using edge design. An online review was led that assembled quantitative information from 800 members. Their reactions of verifiable significance were explored utilizing edge plan assessment and the relapse examination, and SPSS programming was utilized to decide reasons behind increasing in separate from cases in Saudi society. The edge-design analysis produced results that were connected, and it took into account all the 
information. It was found that differing temperaments and personalities between spouses and negligence of marital duties and lack of concern for the husband are factors that have contributed to the increase in divorce cases. On this basis, it is recommended that Saudi Arabia government develop an operational plan to study these causes. Future studies could analyze the data using supersaturated prototypes in which a large number of variables are studied in just a few simulation trials.

\section{Abbreviations}

SPSS: Statistical Package for Social Sciences.

\section{Data Availability}

The data used to support the findings of this study are available within the article and its supplementary materials.

\section{Conflicts of Interest}

The authors declare that there are no conflicts of interests.

\section{Acknowledgments}

The authors are grateful to all participants in the study. This project was funded by the Deanship of Research at University of Ha'il, Saudi Arabia, with project number BA-1903.

\section{Supplementary Materials}

In this section, we put the main manuscript as latex file, namely, ACCed and we put the reference file used in the main file of the scientific paper, which is calibrated from the latex file. We also added the data file used in the scientific paper. (Supplementary Materials)

\section{References}

[1] S. Alghnam, M. Alrowaily, M. Alkelya, A. Alsaif, F. Almoaiqel, and A. Aldegheishem, "The prevalence of seatbelt and mobile phone use among drivers in Riyadh, Saudi Arabia: an observational study," Journal of Safety Research, vol. 66, pp. 33-37, 2018.

[2] J. Hezarjaribi, A. Entezari, and M. Niyyati, "Divorce trends in Iran between 2004-2013," Journal of History Culture and Art Research, vol. 6, no. 4, pp. 1108-1122, 2017.

[3] Anees, Reasons for the Increase in Divorce Rates in Iraqi Society (Diwaniyah Governorate as a Model), Al-adisiyah University, Al Diwaniyah, Iraq, vol. 19, 2016.

[4] A. b. A. R. Aqeel, Divorce: Causes, Prevention, Treatment, Naif Arab University for Security Sciences, Riyadh, Saudi Arabia, 2016.

[5] Z. Alhayajneh and O. M. Wael Abujalban, "The causes of divorce in Jordan and its educational implications," Journal for Educational and Psychological Research and Studies, vol. 3, no. 11, 2018.

[6] A. Majali, The Most Important Social Reasons that Lead to the Occurrence of Divorce from the Point of View of Divorced and Divorced Women in Karak Governorate, Al Al-Bayt University, Mafraq, Jordan, 2016.
[7] O. Al-Jundi, "An investigation of the reasons for divorce among the Palestinian residents of Jerusalem," Bethlehem University Journal, pp. 32-69, 2008.

[8] W. B. S. B. M. Al-Maamari, "Reasons for divorce from the perspective of divorced men and women in the omani society," Amarabac Magazin, vol. 39, no. 3138, pp. 1-39, 2015.

[9] L. Gigy and J. B. Kelly, "Reasons for divorce: perspectives of divorcing men and women," Journal of Divorce \& Remarriage, vol. 18, no. 1-2, pp. 169-188, 1993.

[10] M. Thurnher, C. B. Fenn, J. Melichar, and D. A. Chiriboga, "Sociodemographic perspectives on reasons for divorce," Journal of Divorce, vol. 6, no. 4, pp. 25-35, 1983.

[11] T. T. M. Thi, "Complex transformation of divorce in Vietnam under the forces of modernization and individualism," International Journal of Asian Studies, vol. 18, no. 2, pp. 1-21, 2021.

[12] J. Osafo, K. Oppong Asante, C. A. Ampomah, and A. OseiTutu, "Factors contributing to divorce in Ghana: an exploratory analysis of evidence from court suits," Journal of Divorce \& Remarriage, vol. 62, no. 4, pp. 312-326, 2021.

[13] N. Nakhaee, M. Eslami, M. Yazdanpanah et al., "Reasons for seeking a divorce in Iran," Journal of Social and Personal Relationships, vol. 37, no. 10-11, pp. 2863-2870, 2020.

[14] M. Zuo, S. K. Khosa, Z. Ahmad, and Z. Almaspoor, "Comparison of covid-19 pandemic dynamics in Asian countries with statistical modeling," Computational and Mathematical Methods in Medicine, vol. 2020, Article ID 4296806, 16 pages, 2020.

[15] J. Zhao, Z. Ahmad, and Z. Almaspoor, "Modeling the covid-19 pandemic dynamics in Iran and China," CMC-Computers Materials \& Continua, vol. 67, no. 2, pp. 2111-2122, 2021.

[16] W. Bo, Z. Ahmad, A. R. Alanzi, A. I. Al-Omari, E. Hafez, and S. F. Abdelwahab, "The current covid-19 pandemic in China: an overview and corona data analysis," Alexandria Engineering Journal, 2021, In Press.

[17] C. Elster and A. Neumaier, "Screening by conference designs," Biometrika, vol. 82, no. 3, pp. 589-602, 1995.

[18] T. Alanazi, S. D. Georgiou, and S. Stylianou, "Construction and analysis of edge designs from skew-symmetric supplementary difference sets," Communications in Statistics Theory and Methods, vol. 47, no. 20, pp. 5064-5076, 2018. 